\title{
CALOGÊNESE IN VITRO DE BROMÉLIAS ENDÊMICAS DA CHAPADA DIAMANTINA
}

\author{
Fernanda de Jesus Oliveira Bastos ${ }^{1}$; Andressa Priscila Piancó Santos Lima ${ }^{2}$; Alone \\ Lima-Brito ${ }^{3}$; José Raniere Ferreira de Santana ${ }^{4}$ \\ 1. Bolsista FAPESB, Graduanda em Agronomia, Universidade Estadual de Feira de Santana, e-mail: \\ nandahhbastos@hotmail.com \\ 2. Doutoranda em Recursos Genéticos Vegetais, Universidade Estadual de Feira de Santana, e-mail: \\ andressapianco@gmail.com \\ 3. Professora, Departamento de Biologia, Universidade Estadual de Feira de Santana, e-mail: \\ lima_brito@yahoo.com.br \\ 4. Orientador, Departamento de Biologia, Universidade Estadual de Feira de Santana, e-mail: \\ jose.raniere@gmail.com
}

PALAVRAS-CHAVE: Bromeliaceae; Cultivo in vitro; Calo.

\section{INTRODUÇÃO}

Dentre as plantas endêmicas encontradas na Chapada Diamantina, e que apresentam grande potencial ornamental, destacam-se Neoregelia mисиgensis Leme e Orthophytum mucugense Wand. \& Conc. (Leme, 1998; Wanderley \& Conceição, 2006). Estas são encontradas em pequenas populações sendo alvo de extrativismo predatório e de queimadas que constantemente ocorrem na região, o que torna necessário a realização de estudos que visem à preservação dessas espécies.

Neste sentido, a cultura de tecidos vegetais constitui-se como uma aliada para a propagação e conservação dessas espécies através da micropropagação. Esta técnica pode ser desenvolvida pela embriogênese somática indireta, em que os embriões somáticos se formam a partir do calo que apresenta células em diferentes estádios de diferenciação Guerra et al. (1998). Dentre os fatores que controlam a morfogênese in vitro podemos citar os reguladores de crescimento, estando as citocininas e as auxinas entre os mais utilizados Soares et al. (2011). As auxinas atuam na formação de calos, indução do desenvolvimento de nós e de raízes adventícias Carvalho \& Vidal (2003).

$\mathrm{O}$ estabelecimento in vitro de $N$. mucugensis e $O$. mucugense foi feito com sucesso Bellintani et al. (2007), bem como a multiplicação via organogênese direta Bellintani et al. (2008). No entanto, os autores consideram as taxas obtidas baixas, e sugerem que novas pesquisas sejam realizadas a fim de aumentar a taxa proliferativa das espécies.

Portanto, o objetivo desse trabalho foi estabelecer protocolo de calogênese visando a obtenção de calos com potencial embriogênicos para $N$. mucugensis e $O$. mucugense.

\section{MATERIAL E MÉTODOS}

\section{Material vegetal e meio de cultura}

Plantas germinadas in vitro com 4 meses de idade foram utilizadas como fonte de explantes para realização do experimento. Os explantes foram inoculados em tubos de ensaio contendo $15 \mathrm{~mL}$ de meio de cultura. O meio utilizado foi o MS $1 / 2$ contendo 30gL-1 de sacarose e 7gL-1 de ágar (meio básico). $\mathrm{O}$ pH do meio foi ajustado para 5,8 antes da autoclavagem, sendo realizada à $121^{\circ} \mathrm{C}$ por 15 minutos.

\section{Efeito do 2,4 diclorofenoxiacético - 2,4D em explantes foliares e radiculares de Neoregelia mucugensis}

Os explantes foliares e radiculares com $1 \mathrm{~cm}$ foram inoculados em tubos de ensaio contendo $10 \mathrm{~mL}$ de meio básico acrescido de diferentes concentrações de 2,4 diclorofenoxiacético - 2,4D $(0,00 ; 1,0 ; 2,0 ; 3,0 ; 4,0 \mu \mathrm{M})$. O delineamento experimental 
foi o inteiramente casualizado, com arranjo fatorial de $2 \times 5$, sendo dois tipos de explantes, e cinco concentrações de 2,4D, totalizando 10 tratamentos, com cinco repetições por tratamento e cinco amostras por repetição. Cada amostra com um explante.

\section{Efeito do 2,4 diclorofenoxiacético - 2,4D em explantes foliares de Neoregelia mucugensis}

Os explantes foliares com $1 \mathrm{~cm}$ foram inoculados em tubos de ensaio contendo $10 \mathrm{~mL}$ de meio básico acrescido de diferentes concentrações de 2,4 diclorofenoxiacético $-2,4 \mathrm{D}(0,0 ; 5,0 ; 10,0 ; 15,0 ; 20 \mu \mathrm{M})$. O delineamento experimental foi o inteiramente casualizado, com 5 tratamentos, cada um com seis repetições, e cinco amostras por repetição. Cada amostra com um explante.

\section{Efeito do picloram em explantes foliares de Orthophytum mucugense}

Os explantes foliares com $1 \mathrm{~cm}$ foram inoculados em tubos de ensaio contendo $10 \mathrm{~mL}$ do meio básico acrescido de diferentes concentrações de picloram $(0,00 ; 0,5 ; 1,0$; $1,5 ; 2,0 \mu \mathrm{M})$. O delineamento experimental foi inteiramente casualizado, 5 tratamentos, com seis repetições por tratamento e cinco amostras por repetição. Cada amostra com um explante.

\section{Avaliações}

Para os experimentos I e II após 60 dias foram avaliadas a porcentagem de explante responsivos a formação de calo (\%ERC). Para o experimento III foram avaliados a porcentagem de explante responsivos a formação de calo (\%ERC), e presença de estruturas globulares (PEG).

\section{Condições experimentais}

Todos experimentos foram mantidos em sala de crescimento com temperatura de $26 \pm 3^{\circ} \mathrm{C}$, e ausência de luminosidade.

\section{Análise dos dados}

Os dados foram submetidos à análise de variância (ANOVA) utilizando o programa estatístico SISVAR 5.1 e as médias comparadas pelo Teste de Tukey a 5\% de probabilidade ou analisadas por regressão.

\section{RESULTADOS E/OU DISCUSSÃO}

No experimento com 2,4-D os explantes foliares e radiculares de Neoregelia mucugensis não apresentaram resposta morfogênica, apesar dessa auxina ser muito utilizada na indução de calo, não foi eficaz para este trabalho. Devido a isto, concentrações mais elevadas foram testadas, no entanto, os explantes também não foram responsivos a estas.

A análise de variância apontou efeito significativo $(\mathrm{p} \leq 0,05)$ para as concentrações de picloram na variável porcentagem de explante responsivos (\%ER), e porcentagem de estruturas globulares (\%EG) (Tabela1). Foi observada a formação de calos nos explantes sob efeito deste regulador vegetal, que apresentaram textura friável e coloração bege.

Para o efeito do picloram na \%ER a análise de regressão apresentou o modelo polinomial quadrático, demonstrando que a adição desse regulador ao meio de cultura promoveu um aumento na taxa de formação de calos, alcançando o ponto máximo na concentração de $1,43 \mu \mathrm{M}$ com valor máximo estimado de 40,89\% (Figura 1). Deste ponto em diante ocorre um decréscimo na taxa de explantes responsivos. 
Tabela 1. Análise de variância para porcentagem de explantes responsivos (\%ER), e porcentagem de estruturas globulares (\%EG) sob efeito do picloram.

\begin{tabular}{cccc}
\hline Fonte de variação & GL & \multicolumn{2}{c}{ Quadrado médio } \\
\hline & & $\%$ ER $^{*}$ & $\%$ PEG $^{*}$ \\
\cline { 3 - 4 } Picloram & 4 & 0,483199 & 0,250396 \\
CV $(\%)$ & & 40,08 & 80,19 \\
\hline
\end{tabular}

*Significativo ao nível de 5\% de probabilidade

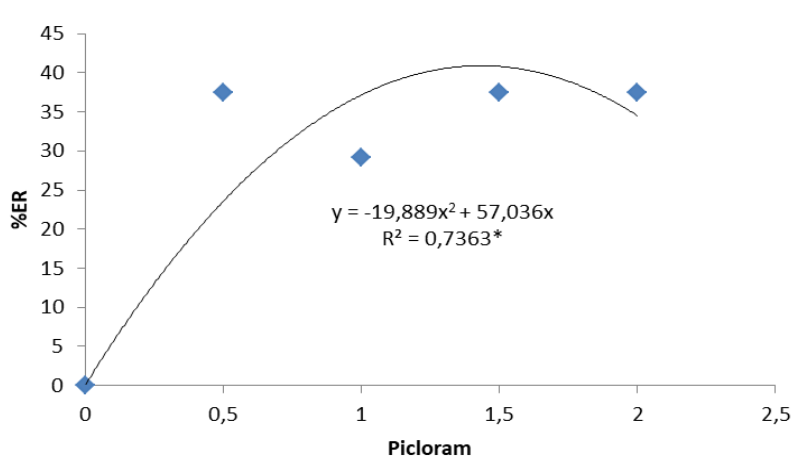

Figura 1. Porcentagem de explantes responsivos em função de diferentes concentrações de picloram, em explantes foliares Orthophytum mucugense, após 60 dias de cultivo.

Esses resultados demostram que possivelmente os explantes foliares de $O$. mucugense, já possuam altas concentrações endógena de auxina, e que a aplicação exógena de baixas concentrações é suficiente para induzir a formação de calo, sendo que concentrações mais elevadas apresenta efeito inibitório.

Observa-se que na ausência de regulador vegetal não houve formação de calos, isto confirma a relevância da auxina neste processo. Visto que o picloram é relatado como uma auxina que induz alta formação de calos Pacheco et al. (2012).

Em relação à \%EG a análise de regressão apontou o modelo polinomial quadrático como mais representativo para esta variável; na ausência do picloram os explantes foliares de $O$. mucugense não apresentaram respostas morfogênicas, sendo que a adição dessa auxina ao meio de cultura promoveu a formação de estruturas globulares que aumentou conforme as concentrações foram elevadas até atingirem o ponto máximo de $1,25 \mu \mathrm{M}$ com o valor estimado de $17,2 \%$; a partir desse pondo essa taxa tende a diminuir (Figura 2). A presença de estruturas globulares nos calos indica o potencial embriogênico dos mesmos, sendo necessário análises histológicas para confirmação de embriogênese.

Esta redução da resposta com concentrações mais elevadas do picloram, observada nas figuras, pode estar relacionada ao fato de que os reguladores vegetais sintéticos ocasionam nos vegetais efeitos similares aos dos hormônios, podendo promover ou inibir os processos metabólicos Albuquerque et al. (2008). Tal resposta varia entre as espécies, entre os tipos de explantes utilizados no cultivo in vitro, bem como dentre os diferentes reguladores vegetais utilizados; que pode ser notado em outros estudos realizados com bromélias. 


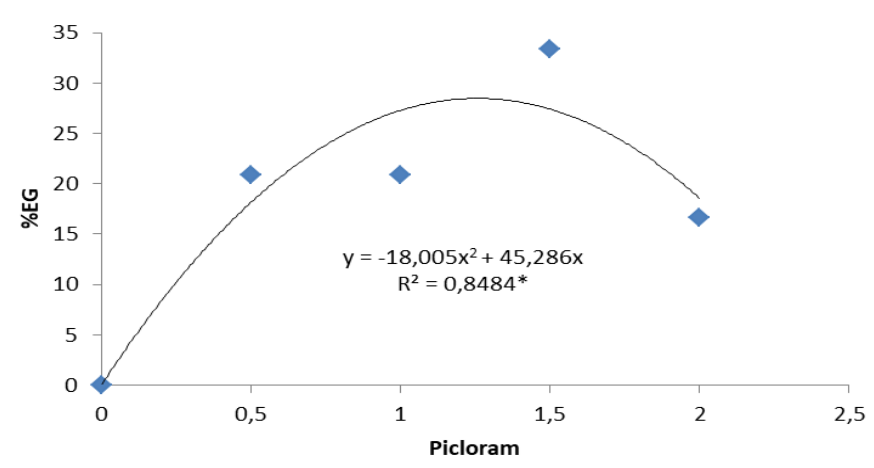

Figura 2. Porcentagem de estruturas globulares em função de diferentes concentrações de picloram, em explantes foliares Orthophytum mucugense, após 60 dias de cultivo.

Isto demonstra que auxinas são necessárias no processo de embriogênese, visto que desempenham função fundamental na indução de embriões na cultura, e também no desenvolvimento morfológico adequado destes embriões (Zimmerman, 1993; Reis et al. 2007).

\section{CONCLUSÃO}

O 2,4-D, nas concentrações utilizadas, não são eficientes para a indução de calos em explante foliar basal e radicular de Neoregelia mucugensis. O picloram é indicado para a indução de calos em explante foliar basal de Orthophytum mucugense.

\section{REFERÊNCIAS}

ALBUQUERQUE, T. C. S. de; MOUCO, M. A. do C.; ALBUQUERQUE NETO, A. A. de.2008. Reguladores de crescimento vegetal na concentração de macronutrientes em videira Itália. Bragantia, p. 553-561.

BELLINTANI, M. C. et al.2007. Estabelecimento in vitro de Orthophytum mucugense e Neoregelia mucugensis, bromélias endêmicas da Chapada Diamantina, Bahia - Brasil. Revista Brasileira de Biociências, Porto Alegre, v. 5, supl. 2, p. 1101-1103.

BELLINTANI, M.C. et al.2008. Resposta regenerativa in vitro de explantes caulinares de bromélias endêmicas da Chapada Diamantina- Bahia. Magistra, v.20, n.4, p.328337.

CARVAlhO, J. M. F. C.; VIDAL, M. S. 2003. Noções de Cultivo de Tecidos Vegetais. Campina Grande.

GUERRA, M. P; TORRES, A. C; TEIXEIRA, J. B. 1998. Embriogênese Somática e Sementes Sintéticas. In: TORRES, A. C.; CALDAS, L. S.; BUSO, J. A. Cultura de tecidos e transformações genética de plantas. Brasília SPI/Embrapa-CNPH, v.1.p. 533558.

LEME, E.M.C.1998.Bromélias da Mata Atlântica. Canistropsis Rio de Janeiro: Salamandra, p.143.

PACHECO G, Garcia R, Lugato D, Vianna M \& Mansur E. 2012. Plant regeneration, callus induction and establishment of cell suspension cultures of Passiflora alata Curtis. Scientia Horticulturae, 144:42-47.

SOARES, F. P. et al.2011. Taxa de multiplicação e efeito residual de diferentes fontes de citocinina no cultivo in vitro de Hancornia speciosa Gomes. Ciência e Agrotecnologia, v. 35, n. 1, p. 152-157, 2011.

WANDERLEY, M. das G. L.; CONCEIÇÃO, A. A. 2006. Notas Taxonômicas e uma nova espécie do gênero Orthophytum Beer (Bromeliaceae) da Chapada Diamantina, Bahia, Brasil. Sitientibus (Série Ciências Biológicas), Feira de Santana, v. 6, n. 1, p.3-8. 